\title{
Aeroelasticity Analysis of High-aspect-ratio Composite Wing
}

\author{
K.X. Liu \& W.Zhou \& X.R.Wang \\ $X i$ 'an High Technology Institute, Xi'an, China
}

\begin{abstract}
The pneumatic elastic model establishing and analysis of the high-aspect-ratio composite wing is an important task for the long-endurance aircraft's design. The pneumatic elastic analysis theory and fluidstructure interaction(FSI) analysis method are applied in this paper to establish the structured finite element model for the high-aspect-ratio composite wing. Based on the analysis of initialized static model, the software MpCCI is used to analyze the model with the bidirectional FSI theory, and discuss the pneumatic elasticity characteristics of the wing model in the coupling state. And the relative structure and flow field parameters are supported.
\end{abstract}

KEYWORD: high aspect ratio; composite; fluid structure interaction; pneumatic elasticity

\section{FOREWORD}

The Development of excellent aerodynamic longendurance aircraft, over the years has been the emphasis on national aerospace research staff. The high-altitude long-endurance unmanned reconnaissance aircraft, such as "Predator", "Global Hawk" in the United States, is the outstanding representative of this type. The high aspect ratio aircraft, whose wing aspect ratio is generally above 20 ,has the characteristic of high lift to drag ratio, so it has the characteristic of long blank time and far voyage. wing's soft, anisotropy and high-aspect-ratio leads to wing aircraft's strong and large bending and torsion elastic deflection in a normal flight. The using of composite material, having the characteristics of Lightweight, high specific strength and high specific stiffness, makes the design of light quality, line length, high-performance aircraft possible. Aeroelastic analysis carries out mainly in the frequency domain, considering that wing is in simple harmonic oscillation when the flutter occurs, to calculate the aerodynamic flutter frequency and the frequency domain. Research on high-aspect-ratio wing's flutter problem has always been a hot issue in the coupling field.

Bein $\mathrm{T}$ and Friedmann $\mathrm{P}[1]$ discussed the similarities and differences of the high-order piston theory, potential flow method, Euler equation and NS equation in calculating the unsteady aerodynamics of hypersonic board. Pidaparti[2] studied the nonlinear flutter characteristics of the composite material panels. Huang Chunsheng[3] used double precision finite volume upwind scheme to solve the supersonic flow field to achieve wing's temperature field coupling calculation and numerical analysis in the flow field flowing solid wall. Currently, in most of the literature[1,2,3] the structural model was established by applying finite element method to calculate the elastic piston aerodynamic theory. High-aspect-ratio and soft wing causes airplane wing to engender considerable distortion in normal flighting conditions. Under the aerodynamic loads, high aspect ratio wing has a great deformation. And the large deformation will affect redistribution of the aerodynamic loads and the performance of the whole machine greatly. This aerodynamic/structural coupling characteristics make the aircraft flight speed limited, flying qualities affected, aeroelastic characteristics and the natural frequency of the wing produce changed so significantly that conventional methods for solving linear systems of small deformation assumptions no longer apply. So it must be considered in the analysis due to large deformation changes in the structure of the geometry and balance relations to form a socalled nonlinear large displacement problem.

MpCCI as the standard software of fluid-structure interaction, based on two cross-iterative methods, has such advantages as numerical proven, reliable, convergence, good stability and a smaller calculation amount[1]. Given MpCCI software has the advantages of integrating finite element method and finite volume method to solve fluid-structure 
interaction problems by combining multi-solver, this paper, on the basis of a finite element model of the composite high-aspect-ratio wing, establishes finite element analysis dynamics model according to the relevant test results, and analyse the aeroelastic mechanical structure and flow field applying the MpCCI software[1].

\section{AEROELASTIC THEORY ANALYSIS BASED ON MPCCI}

The wing's aeroelastic area mainly studys the problems of the aerodynamic stability and the elastic dynamic aerodynamic response.Aeroelastic stability problem mainly is flutter.The core calculation of dynamic aeroelastic is to calculate the unsteady aerodynamic forces, especially for flutter analysis.In order to accurately determine the critical flutter speed of the wing, the unsteady aerodynamics of wing by vibration should be researched.

Wing aeroelastic problem solving with MpCCI, shown in Figure 1, because it is the pneumatic fluid solid coupling analysis of elastic, fluid software uses the unsteady method and structure analysis software uses the transient solver. In a time step, the fluid transferres the gas power on the coupling face to the structure analysis software ABAQUS, then ABAQUS deliveres deformation on the coupling surface to the fluid software FLUENT, to facilitate fluid software re-calculating the load distribution, loop iterating until the emergence of periodic stability of stable or arriving the transient analysis time.

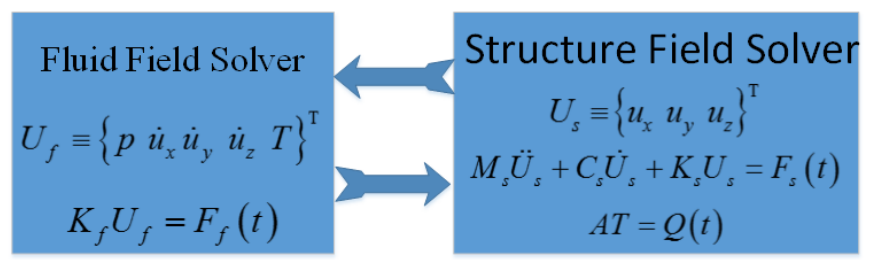

Figure 1 Fluid-structure interaction analysis principle

In the coupling analysis of the wing, the fluid analysis software FLUENT plays a role of leading and controlling. As shown in Figure 2, firstly, the fluid analysis software initializes outflow fluid field. And after the initialization is completed, the fluid analysis software passes the force of wing's coupling fluid surface to the solid analysis software ABAQUS. Then the solid analysis software calculates the displacement and stress of each node on the coupling surface in this moment. After the initial calculation in the solid software is completed, ABAQUS passes nodal displacement of the coupling region to the software FLUENT as the basis of the moving boundary on the wing's coupling surface. At this time step the fluid software advances time to the next moment to complete a flow simulation in this moment, and passes force of the coupling region to the solid analysis software. When the calculation in the solid analysis software is completed, the solid analysis software passes the fluid displacement to fluid analysis software and so on until coupling process is completed. Because the grid of both parts in the coupling region cannot be matched, MpCCI achieves to transfer and interpolate between the two softwares and store the data of the structure field and outflow field to the relative documents.

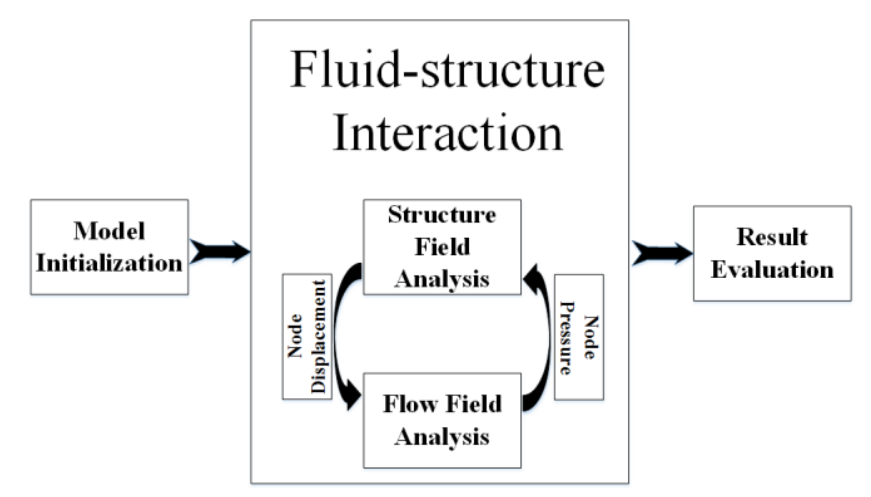

Figure 2 Fluid-structure interaction analysis process

\section{EXAMPLE AND RESULTS ANALYSIS}

\subsection{Problem description}

Wing's aeroelastic problem is a classical problem in fluid-structure coupling. The traditional analysis method regards the wing as rigid body, not considering the elastic deformation, through the CFD software to calculate the flow field near the wing. MpCCI is calculated based on the coupling of parallel code interface. It can also operate the structure and fluid software to achieve the fluidstructure coupling, and predict the real situation of wing's aeroelastic problems. Using structure analysis software ABAQUS to solve the structure's deformation and stress distribution under the action of flow field, the impact and deformation of solids motion on the whole flow field is calculated through the software Fluent.

\subsection{Model establishment}

The aerofoil model used in this article is NACA 65 (2)-415. The research subject is carbon fiber composite scaled wings whose aspect ratio is 24 . Its aerofoil model mesh is shown in Figure 3. Semiwingspan $\mathrm{L}=9.5 \mathrm{~m}$, width of the wing's root $\mathrm{D}_{1}$ $=1 \mathrm{~m}$, width of the tip $\mathrm{D}_{2}=0.5 \mathrm{~m}$, elastic modulus $\mathrm{E}_{1}=250 \mathrm{GPa}$, density $=1500 \mathrm{~kg} / \mathrm{m}^{3}$, Poisson's ratio $=0.3$. The boundary conditions are that the displacement of wing's ending is fixed and the other faces freedom. Except for the fixed face, the other three faces are the coupling faces. The fluid part adopts a tetrahedral unstructured mesh, and uses the ideal gas as the density model. 
Figure $32 \mathrm{D}$ and 3D aerofoil

\subsection{Structure field analysis}

When the aircraft in the air flow, and the interaction of the elastic force, and the inertial force of the aerodynamic wing easily generated shock (shown in Figure 4), so that the wing is deformed, thus affecting the stability of an internal structure of the wing and the flow field distribution on the surface.

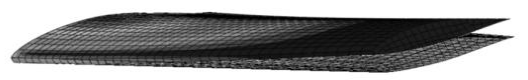

Figure 4 Wing's vibration

The example is set in $19000 \mathrm{~m}$ altitude, atmospheric pressure is about $9000 \mathrm{~Pa}$, test flight speed is 100 to $400 \mathrm{~m} / \mathrm{s}$, the flight's angle of attack is $-5^{\circ}$ to $5^{\circ}$, flighting at 0 degrees angle of attack, respectively when the speed is $100 \mathrm{~m} / \mathrm{s}, 200 \mathrm{~m} / \mathrm{s}$, $300 \mathrm{~m} / \mathrm{s}$ and $400 \mathrm{~m} / \mathrm{s}$, the wing's internal stress concentration will appear, shown in Figure 5:

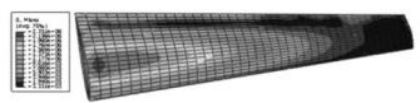

$100 \mathrm{~m} / \mathrm{s}$

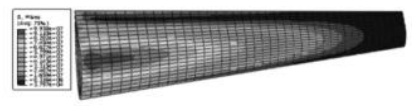

$300 \mathrm{~m} / \mathrm{s}$

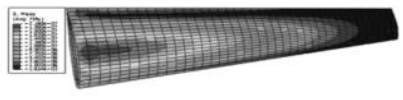

$200 \mathrm{~m} / \mathrm{s}$

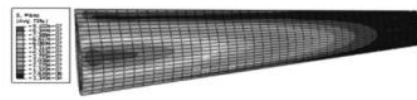

$400 \mathrm{~m} / \mathrm{s}$
Figure 5 the wing stress nephogram under $0^{\circ}$ angle of attack

The maximum stress value of the upper surface the wing's thickness place changes with the speed which is shown in Figure 6, the stress is gradually reduced from the wing's root to the tip, close to linear variation; the stress in the same position increases as the speed increases.

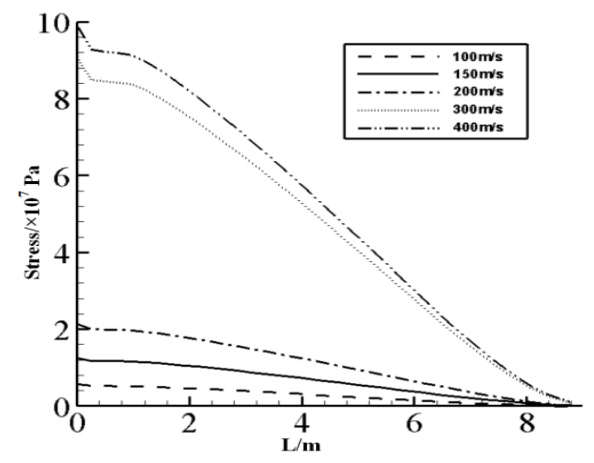

Figure 6 Stress Variation Figure at different speeds
When the aircraft's speed is $150 \mathrm{~m} / \mathrm{s}$, and respectively, the flight angle of attack is $-5^{\circ}, 0^{\circ}$ and $5^{\circ}$, the stress nephogram of the wing's lower surface is shown in Figure 7:

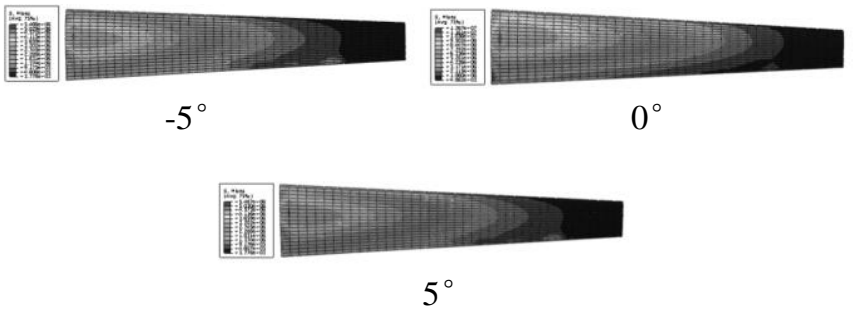

Figure 7 stress nephogram at $150 \mathrm{~m} / \mathrm{s}$

The maximum stress value at the thickness of the wing's lower surface varies with the speed which is shown in Figure 8. The stress decreases from the wing's root to the tip, the stress at the same position of the $0^{\circ}$ angle of attack is bigger than the stress of the other angle of attack. The stress values of $-5^{\circ}$ and $5^{\circ}$ angle of attack is close.

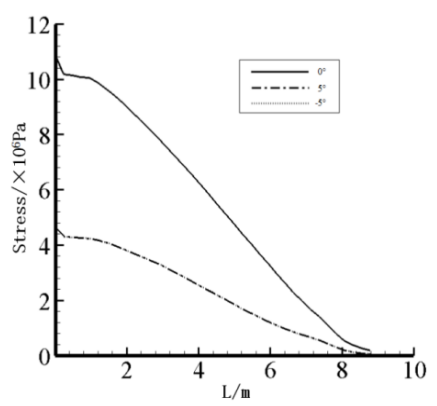

Figure 8 Stress Variation Figure of different angle of attack

\subsection{Flow Field Analysis}

When the aircraft is flighting at a speed of $150 \mathrm{~m} / \mathrm{s}$ and the angle of attack is 0 degrees, as is shown in Figure 9,10, lift coefficient is measured 1.256, the drag coefficient 0.056 , lift-drag ratio of the aircraft is in line with the theoretical characteristics of lift-drag ratio.

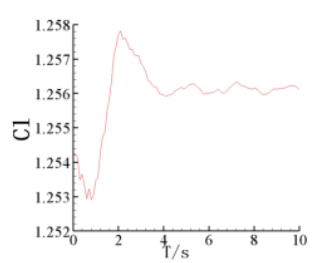

Figure 9 Variation of lift coefficient

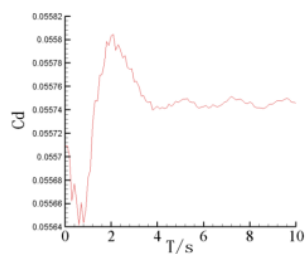

Figure 10 Variation of drag coefficient 
As is shown in Figure 11, in the traditional wing's external flow field analysis, approximately, the static stress of wing's surface evenly distributes, some changes are only at the front of the wing. while referencing two-way fluid-structure interaction theory, considering the impact of structure deformation to flow field, as is shown in Figure 12, the wing's static force field distribution is significantly different, in the front wing the static pressure is at the maximum, dynamic pressure at the minimum, and in the thick wing the dynamic pressure is at maximum, static pressure at the minimum.

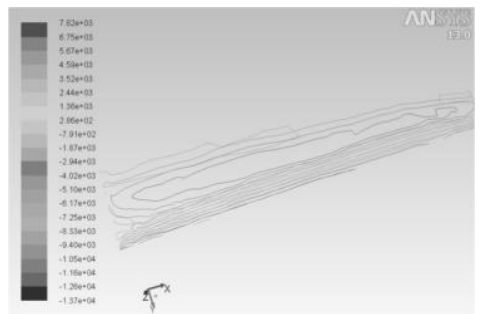

Figure 11 Unidirectional coupling hydrostatic

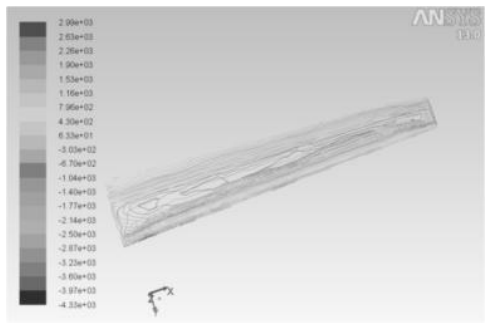

Figure 12 Two-way coupling hydrostatic

When the speed of high-aspect-ratio aircraft is respectively at $100 \mathrm{~m} / \mathrm{s}, 200 \mathrm{~m} / \mathrm{s}, 300 \mathrm{~m} / \mathrm{s}, 400 \mathrm{~m} / \mathrm{s}$, relative static pressure distribution of the wing surface is shown in Figure 13, the wing's surface static pressure increases with increasing velocity throughout, static has a minimum value at the thickness of the wing, and there is a maximum value at the front of the wing.

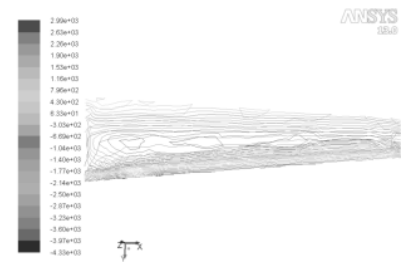

$100 \mathrm{~m} / \mathrm{s}$

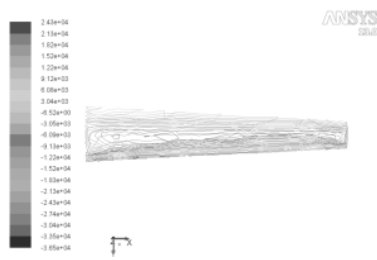

$300 \mathrm{~m} / \mathrm{s}$

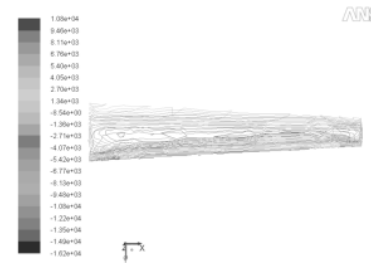

$200 \mathrm{~m} / \mathrm{s}$

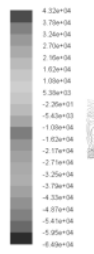

$400 \mathrm{~m} / \mathrm{s}$
Figure 13different velocity wing's surface hydrostatic flow

\section{CONCLUSION}

(1) According to the MpCCI principle to solve the dynamic elastoplastic problems, because the common calculating result is used as the initial field of unsteady calculation, it can greatly reduce the time of calculating dynamic elastic problems, and can be applied to practical engineering problems. And bidirectional coupling dynamics used to explain high-aspect-ratio wing's state in the air is more close to the real state and more reasonable.

(2) Stress throughout the wing increases with the increase of speed. When the curvature at the wing deformation is little, the decay rate of stress is approximately linear, and there is a maximum value at the wing's root.

(3) Static pressure on wing's surface increases with the flow rate increasing, in the front of wing static pressure has the maximum value, the dynamic pressure has the minimum value. The thickness of wing, the dynamic pressure has the maximum value, static pressure has the minimum value. And they all have characteristic of high lift to drag ratio. Using the fluid-structure coupling theory to analyse wing flow field distribution is more close to the true value, which can provide more reasonable and efficient reference data for engineering practice.

\section{REFERENCES}

[1] Bein T,Friedmann P,etal. Hypersonic flutter of a curved shallow panel with aerodynamic heating. 34th AIAA/ASME/ASCE/AHS/ASC Structures, Structural Dynamics and Materials Conference. Washington DC: 1993, 1-15.

[2] Pidaparti R. Free vibration and flutter of damaged composite panels. Composite structures, 1997, 38(1):477481.

[3] Huang Chunsheng, Wu Jie, Xu Fan Kei aircraft flow field and temperature field structure coupled numerical analysis. Mechanics and practice, 2004, 26(002):24-26.

[4] $\mathrm{Xu}$ Yun, Wang Jingyan, Yang Chao flutter wing is calculated based on hypersonic air piston theory of elasticity National Symposium Shanghai: 2003, 123-124, 2010, 30(6): 1-4.

[5] Full-Wei Cho, Fang Mingxia supersonic aircraft wingbody combination flutter noise and vibration control study.

[6] Liu da xiang aircraft engine design manual Beijing: Aviation Industry Press, 2000.

[7] Zhang Weiwei, YE Zheng-yin aeroelastic stability analysis transonic aerodynamics reduced-order model based on computational mechanics, 2007, 28 (2): 768-772.

[8] Wei Suili. Oriented fluid-structure interaction engineering solutions. Third China CAE Engineering Analysis Technology Conference Proceedings, 2007. 